\title{
The impact of fluid status and decremental PEEP strategy on cardiac function and lung and kidney damage in mild-moderate experimental acute respiratory distress syndrome.
}

Nazareth N. Rocha

Universidade Federal Fluminense

Cynthia S. Samary

Universidade Federal do Rio de Janeiro Faculdade de Medicina

Mariana A. Antunes

Universidade Federal do Rio de Janeiro

Milena V. Oliveira

Universidade Federal do Rio de Janeiro

Matheus R. Hemerly

Universidade Federal do Rio de Janeiro

Patrine S. Santos

Universidade Federal do Rio de Janeiro

Vera L. Capelozzi

Universidade Federal do Rio de Janeiro

Fernanda F. Cruz

Universidade Federal do Rio de Janeiro

John J. Marini

University of Minnesota

Pedro L. Silva

Universidade Federal do Rio de Janeiro

\section{Paolo Pelosi}

Universita degli Studi di Genova

Patricia R. M. Rocco ( $\sim$ prmrocco@biof.ufrj.br)

Universidade Federal do Rio de Janeiro https://orcid.org/0000-0003-1412-7136

\section{Research}

Keywords: mechanical ventilation, PEEP, inflammation, fluids, kidney, heart

Posted Date: August 12th, 2020 
DOI: https://doi.org/10.21203/rs.3.rs-56032/v1

License: (c) (i) This work is licensed under a Creative Commons Attribution 4.0 International License. Read Full License 


\section{Abstract \\ Background}

We evaluated the effects of abrupt versus gradual positive end-expiratory pressure (PEEP) decrease, combined with standard versus high-volume fluid administration, on lung, heart, and kidney damage in an established model of acute respiratory distress syndrome (ARDS).

\section{Methods}

Thirty-five Wistar rats received endotoxin intratracheally. After $24 \mathrm{~h}$, they were treated with Ringer's lactate [standard $(10 \mathrm{~mL} / \mathrm{kg} / \mathrm{h})$ or high $(30 \mathrm{~mL} / \mathrm{kg} / \mathrm{h})$ fluids]. For $30 \mathrm{~min}$, all animals were mechanically ventilated with tidal volume $=6 \mathrm{~mL} / \mathrm{kg}$ and $\mathrm{PEEP}=9 \mathrm{cmH}_{2} \mathrm{O}$ (to keep alveoli open), then randomized to undergo abrupt or gradual $\left(0.2 \mathrm{cmH}_{2} \mathrm{O} / \mathrm{min}\right.$ for $\left.30 \mathrm{~min}\right)$ PEEP decrease, from 9 to $3 \mathrm{cmH}_{2} \mathrm{O}$. After this period, animals were further ventilated for 10 minutes at PEEP $=3 \mathrm{cmH}_{2} \mathrm{O}$, euthanized, and then lungs and kidney removed for molecular biology analysis.

\section{Results}

At the end of the experiment, left and right ventricular end-diastolic areas were greater in animals treated with high compared to standard fluid administration, regardless of PEEP decrease rate. The PAT (pulmonary acceleration time)/PET (pulmonary ejection time) ratio was lower in abrupt compared to gradual PEEP decrease, independent of fluid status, suggesting higher pulmonary arterial pressure in rats undergo abrupt PEEP decrease. Animals treated with high fluids and abrupt PEEP decrease exhibited greater diffuse alveolar damage and higher expression of interleukin-6 (pro-inflammatory marker) and vascular endothelial growth factor (endothelial cell damage marker) compared to the other groups. Standard fluid administration associated with gradual PEEP decrease increased zonula occludens-1 expression, suggesting epithelial cell preservation. Club cell-16 protein expression, an alveolar epithelial cell damage marker, was higher in abrupt compared to gradual PEEP decrease, regardless of fluid status. Acute kidney injury score and gene expression of kidney injury molecule-1 was higher in high compared to standard fluid administration, independent of PEEP strategy.

\section{Conclusion}

In experimental mild-moderate ARDS, decreasing PEEP abruptly increased pulmonary arterial hypertension, independent of fluid status. The combination of abrupt PEEP decrease and high fluid administration led to greater lung and kidney damage. This information adds to the growing body of evidence that supports gradual transitioning of ventilatory patterns and warrants directing additional investigative effort into vascular and deflation issues that impact lung protection. 


\section{Background}

Lung-protective strategies aimed at preventing ventilator-induced lung injury (VILI) have focused strictly on the regulation of airspace pressures, excursions, and frequencies [1]. By comparison, events affecting the opposite (vascular) side of the gas-exchanging membrane have been relatively neglected [1]. Yet, there is ample reason to conclude that events within the gas and vascular spaces interact in VILI pathogenesis. Convincing experimental evidence indicates that microvascular pressures and flows strongly influence lung edema and VILI expression [2,3]. Moreover, fluid balance, a presumed correlate of vessel filling, relates directly to clinical outcomes for as yet incompletely defined reasons [4]. The rates at which ventilatory interventions are imposed or withdrawn may also contribute to VILI risk. Gradual increases in tidal volume $\left(V_{T}\right)[5]$ PEEP [6] and recruiting pressures $[7,8]$ appear to be better tolerated than sudden ones, presumably by allowing beneficial distribution of stress and strain. On the deflation side, data gathered in recent years from small-animal models with previously healthy lungs demonstrate the adverse influence of abruptly releasing high-level PEEP [9]. This observation has been attributed primarily to cardiovascular compromise owing to the initial "surge" of translocating fluid volumes from peripheral to central vascular compartments. In experimental acute respiratory distress syndrome (ARDS), however, alveoli have different time constants and lung tissue sensitivity to vascular volume fluxes due to atelectasis and edema. In theory, the lung may be influenced not only by deflation kinetics but also by the pace of PEEP release.

Fluid administration, like any other treatment, might induce significant side effects in experimental ARDS. Experimental [10] and clinical [11] studies reported that reducing lung vascular hydrostatic pressures decreases lung edema in ARDS, likely due to favorable effects on Starling forces and attenuated lung inflammation [12]. Despite a considerable body of published evidence that implicates the importance of fluid volume status and ventilatory transitions in VILI and organ dysfunction, to our knowledge, the relative effects of abrupt as opposed to gradual release of PEEP on the lung, heart, and other vital organs have not been investigated. Thus, the aim of the present study was to evaluate the effects of abrupt versus gradual PEEP release-combined with standard or high fluid volumes-on the lung, heart, and kidney in an established animal model of ARDS.

\section{Material And Methods}

\section{Study approval}

This study was approved by the Animal Care and Use Committee (CEUA: 122/18) of the Health Sciences Center, Federal University of Rio de Janeiro, Rio de Janeiro, Brazil. All animals received humane care in compliance with the "Principles of Laboratory Animal Care" formulated by the National Society for Medical Research and the U.S. National Academy of Sciences Guide for the Care and Use of Laboratory Animals. Animals were housed at a controlled temperature $\left(23^{\circ} \mathrm{C}\right)$ and controlled light-dark cycle $(12-12$ h), with free access to water and food. 


\section{Animal Preparation and Experimental Protocol}

Thirty-five male Wistar rats (age 8-10 weeks, body weight 291 $\pm 75 \mathrm{~g}$ ) were used. Rats were anesthetized by inhalation of sevoflurane 1.0\% (Sevorane $\AA$; Cristália, Itapira, SP, Brazil) and received Escherichia coli lipopolysaccharide (LPS: $9.6 \times 10^{6} \mathrm{EU} / \mathrm{mL}$ in $200 \mu \mathrm{L}$ of saline solution) intratracheally (i.t.) to induce experimental acute respiratory distress syndrome [5] Twenty-four hours after ARDS induction, animals were premedicated intraperitoneally (i.p.) with $10 \mathrm{mg} / \mathrm{kg}$ diazepam (Compaz ${ }^{\circledR}$, Cristália, Itapira, SP, Brazil), followed by $100 \mathrm{mg} / \mathrm{kg}$ ketamine (Ketamin-S ${ }^{\circledR}$, Cristália, Itapira, SP, Brazil) and $2 \mathrm{mg} / \mathrm{kg}$ midazolam (Dormicum ${ }^{\circledR}$, União Química, São Paulo, SP, Brazil). After local anesthesia with $2 \%$ lidocaine $(0.4 \mathrm{~mL})$, a midline neck incision and tracheostomy were performed. An intravenous (i.v.) catheter (Jelco 24G, Becton, Dickinson and Company, New Jersey, NJ, USA) was inserted into the tail vein, and anesthesia induced and maintained with midazolam $(2 \mathrm{mg} / \mathrm{kg} / \mathrm{h})$ and ketamine $(50 \mathrm{mg} / \mathrm{kg} / \mathrm{h})$. A second catheter (18G, Arrow International, USA) was then placed in the right internal carotid artery for blood sampling and gas analysis (Radiometer ABL80 FLEX, Copenhagen NV, Denmark), as well as monitoring of mean arterial pressure (MAP) (Networked Multiparameter Veterinary Monitor LifeWindow 6000V; Digicare Animal Health, Boynton Beach, FL, USA). Heart rate (HR), MAP, and rectal temperature were continuously monitored (Networked Multiparameter Veterinary Monitor LifeWindow 6000V, Digicare Animal Health, Florida, USA). Body temperature was maintained at $37.5 \pm 1^{\circ} \mathrm{C}$ using a heating bed. Animals in dorsal recumbency were paralyzed with pancuronium bromide $(2 \mathrm{mg} / \mathrm{kg}$, i.v.) and their lungs mechanically ventilated (Servo-i, MAQUET, Solna, Sweden) in volume-controlled mode (VCV) with constant inspiratory airflow, $\mathrm{V}_{\mathrm{T}}=6 \mathrm{~mL} / \mathrm{kg}$, respiratory rate $(\mathrm{RR})$ to maintain $\mathrm{V}_{\mathrm{E}}=160 \mathrm{~mL} / \mathrm{min}$, zero end-expiratory pressure (ZEEP), $\mathrm{FiO}_{2}=0.4$, and an inspiratory-expiratory ratio of 1:2 (BASELINE). Arterial blood gases and echocardiography were evaluated. PEEP was then increased to $9 \mathrm{cmH}_{2} \mathrm{O}$ and, at the same time, animals were randomized to receive standard [(10 ml/kg (NORMO)] or high [30 mL/kg/h (HIGH)] volume of Ringer's lactate (B. Braun, Crissier, Switzerland), continuous intravenous administration until the end of the study. For $30 \mathrm{~min}$, all animals were mechanically ventilated with tidal volume $=6 \mathrm{~mL} / \mathrm{kg}$ and $P E E P=9$ $\mathrm{cmH}_{2} \mathrm{O}$ (to keep alveoli open), then randomized to undergo abrupt or gradual (0.2 $\mathrm{cmH}_{2} \mathrm{O} / \mathrm{min}$ for $30 \mathrm{~min}$ ) PEEP decrease, from 9 to $3 \mathrm{cmH}_{2} \mathrm{O}$ (Fig. 1). After this period, animals were further ventilated for 10 minutes at $\mathrm{PEEP}=3 \mathrm{cmH}_{2} \mathrm{O}$. At the end of the experiment, arterial blood gases, echocardiography, and respiratory system mechanics were assessed (FINAL), and heparin (1000 IU) was injected into the tail vein. All animals were killed by overdose of sodium thiopental $(60 \mathrm{mg} / \mathrm{kg}$ i.v.) and the trachea was then clamped at $P E E P=3 \mathrm{cmH}_{2} \mathrm{O}$. Lungs and kidney were then extracted for histology and molecular biology analysis. Seven animals received LPS intratracheally but were not mechanically ventilated [non-ventilated (NV) animals] and, after $24 \mathrm{~h}$, were euthanized and had their lungs and a kidney removed for molecular biology analysis.

\section{Data Acquisition and Processing}

Airflow and airway pressure were continuously recorded throughout the experiments $[5,13,14] . V_{T}, R R, V_{E}^{\prime}$ were calculated. Respiratory system mechanics was assessed by occluding the airways at end- 
inspiration for 5 seconds until a respiratory system plateau pressure (Pplat, ${ }_{\mathrm{RS}}$ ) was reached. Respiratory system driving pressure ( $(\mathrm{DP}, \mathrm{RS})$ was calculated as the difference between Pplat, ${ }_{\mathrm{RS}}$ (post end-inspiratory pause) and PEEP. All signals were amplified in a four-channel signal conditioner (SC-24, SCIREQ, Montreal, QC, Canada), and sampled at $200 \mathrm{~Hz}$ with a 12-bit analog-to-digital converter (National Instruments; Austin, Texas, USA). Mechanical data were computed offline by a routine written in MATLAB (Version R2007a; The Mathworks Inc., Natick, Massachusetts, USA).

\section{Transthoracic Echocardiography}

Shaved animals were placed in the dorsal recumbent position. Transthoracic echocardiography was performed by an expert (NNR) blinded to group allocation, using an UGEO HM70A system (Samsung, São Paulo, Brazil) equipped with a linear phased-array probe $(8-13 \mathrm{MHz})$. Images were obtained from the subcostal and parasternal views. Transthoracic echocardiography was performed [15] and the following parameters analyzed: right (RV) and left ventricular (LV) areas, as well as right ventricular cardiac output (RVCO). Pulsed-wave Doppler was used to measure the ratio between pulmonary acceleration time (PAT) and pulmonary ejection time (PET), which is an indirect index of pulmonary arterial hypertension [16]. All parameters followed American Society of Echocardiography and European Association of Cardiovascular Imaging recommendations [15].

\section{Histology}

\section{Diffuse Alveolar Damage}

The lungs and heart were removed en bloc. The left lung was frozen in liquid nitrogen and immersed in formaldehyde solution (4\%), embedded in paraffin, cut longitudinally in the central zone by means of a microtome into three slices, each $4 \mu \mathrm{m}$ thick, and stained with hematoxylin-eosin for histological analysis $[5,13]$. Photomicrographs at magnifications of $\times 100, \times 200$, and $\times 400$ were obtained from eight non-overlapping fields of view per section using a light microscope (Olympus BX51, Olympus Latin America Inc., Brazil). Diffuse alveolar damage (DAD) was quantified using a weighted scoring system by two investigators (M.V. and V.L.C.) blinded to group assignment and independently, as described elsewhere [17]. Briefly, scores of 0 to 4 were used to represent interstitial edema, overdistension, alveolar collapse, septal inflammation, and alveolar hemorrhage, with 0 standing for no effect and 4 for maximum severity. Additionally, the extent of each scored characteristic per field of view was determined on a scale of 0 to 4 , with 0 standing for no visible evidence and 4 for complete involvement. Scores were calculated as the product of severity and extent of each feature, on a range of 0 to 16 . The cumulative DAD score was calculated as the sum of each score characteristic and ranged from 0 to 80 , as described elsewhere [17].

\section{Acute Kidney Injury Score}

Kidney slices were stained with hematoxylin-eosin and periodic acid-Schiff and observed under light microscopy for qualitative and quantitative analysis. Semiquantitative data were obtained from high- 
resolution photomicrographs. Fifteen non-overlapping images of tubular tissue (cortex and outer medulla) were randomly obtained with a $\times 40$ objective lens, from each kidney section ( $n=8 /$ group) stained with H\&E and PAS (tubular profiles). Histological findings were graded from 0 to 4 ( 0 , no change; 1 , changes affecting $25 \%$ of the field of view; 2 , changes affecting $25-50 \% ; 3$, changes affecting $51-$ $75 \%$, and 4 , changes affecting $>75 \%$ of the field), according to the area affected by the features of interest (edema, tubular cell vacuolization, deranged brush border in proximal tubular epithelia, tubular cell death/desquamation, and inflammation). The final kidney injury score in each rat was expressed as the sum of all values of all features obtained and ranged from 0 to 20 [18].

\section{Transmission Electron Microscopy}

Three slices $(2 \times 2 \times 2 \mathrm{~mm})$ were cut from three different segments of the left lung and fixed $(2.5 \%$ glutaraldehyde) for electron microscopy. On each lung electron microscopy image (20 fields per animal), degree of interstitial edema, damage to basement membrane, extracellular matrix damage, type II epithelial cell damage, and endothelial cell damage were graded on a five-point, semiquantitative, severity-based scoring system as follows: $0=$ normal lung parenchyma, 1 to $4=$ changes in 1 to $25 \%, 26$ to $50 \%, 51$ to $75 \%$, and 76 to $100 \%$ of examined tissue, respectively [19].

All histological analyses were performed in a blinded manner.

\section{Biological Markers}

Quantitative real-time reverse transcription polymerase chain reaction (RT-PCR) was used. In lung tissue, gene expression of biomarkers associated with inflammation (interleukin [IL]-6), tight junction (zona occludens-1 [ZO-1], epithelial cell damage (club cell secretory protein 16 [CC16]), extracellular matrix damage (versican and syndecan-1), and endothelial cell damage (vascular endothelial growth factor [VEGF]) were measured. In kidney tissue, gene expressions of biomarkers associated with renal injury (kidney injury molecule [KIM]-1 and neutrophil gelatinase associated lipocalin [NGAL]) and inflammation [IL-6] were evaluated. The primer sequences are listed in Additional File 1, Table S1. Central slices of the right lung and kidney were cut, flash-frozen by immersion in liquid nitrogen, and stored at $-80{ }^{\circ} \mathrm{C}$. For each sample, the expression of each gene was normalized to the acidic ribosomal phosphoprotein P0 (36B4) housekeeping gene [20] and expressed as fold change relative to NV group, using the $2^{-\Delta \Delta C t}$ method, where $\Delta \mathrm{Ct}=\mathrm{Ct}$ (target gene) $-\mathrm{Ct}$ (reference gene) [21]

\section{Statistical Analysis}

Sample size was calculated based on pilot studies, which detected differences in IL-6 between abrupt and gradual PEEP decrease under high fluid administration. A sample size of 7 rats per group would provide the appropriate power $(1-b=0.8)$ to identify significant differences in IL-6, taking into account the effect size $d=2.0$, a two-sided $t$ test, and a sample size ration of 1 (G*Power 3.1.9.2., University of Dusseldorf, Dusseldorf, Germany). Normality and the equality of variance were evaluated by Kolmogorov-Smirnov test with Lilliefors' correction and Levene's median test, respectively. Two-way ANOVA followed by Tukey's 
test was used to compare abrupt and gradual PEEP release under standard and high fluid volume conditions. Parametric data were expressed as mean $\pm S D$, while non-parametric data were expressed as median (interquartile range). All tests were carried out in GraphPad Prism 8.00 (GraphPad Software, La Jolla, CA, USA). Significance was established at $p$ value less than 0.05 .

\section{Results}

No mortality was observed in any group during these experiments. At FINAL, the mean volumes of fluids injected were $6.9 \pm 2.5 \mathrm{~mL}$ in the group treated with standard fluid administration (NORMO) with abrupt PEEP decrease (FAST), $16.1 \pm 7.2 \mathrm{~mL}$ in the high fluid administration (HIGH) with abrupt PEEP decrease group, $6.0 \pm 1.5 \mathrm{~mL}$ in the standard fluid administration with gradual PEEP decrease (SLOW) group, and $15.4 \pm 1.9 \mathrm{~mL}$ in high fluid administration with gradual PEEP decrease group. At BASELINE (ZEEP), oxygenation and echocardiographic parameters did not differ among groups, suggesting similar degrees of lung and cardiac damage (Additional File 2, Table S2). Mean arterial pressure remained above $70 \mathrm{mmHg}$ throughout the experiments.

At FINAL, $\mathrm{pHa}, \mathrm{PaO}_{2} / \mathrm{FiO}_{2}, \mathrm{PaCO}_{2}, \mathrm{HCO}_{3}{ }^{-}$(Additional File 3, Table S3), $\mathrm{V}_{\mathrm{T}}, \mathrm{RR}, \mathrm{V}^{\prime}{ }_{\mathrm{E}}$, and Ti/Ttot (Table 1 ) did not differ between groups. In animals treated with high fluid administration, $\mathrm{Pplat}{ }_{\mathrm{RS}}$ and $\Delta \mathrm{P}_{\mathrm{RS}}$ were higher in abrupt compared to gradual PEEP decrease (Table 1). In the presence of standard fluid administration, no significant differences were observed in $\mathrm{Pplat}_{\mathrm{RS}}$ or $\Delta \mathrm{P}_{\mathrm{RS}}$ between abrupt and gradual PEEP decrease groups. 
Table 1

Respiratory parameters at FINAL

\begin{tabular}{|c|c|c|c|}
\hline & FLUIDS & PEEP & FINAL \\
\hline \multirow[t]{4}{*}{$\mathrm{V}_{\mathrm{T}}(\mathrm{mL} / \mathrm{kg})$} & NORMO & \multirow[t]{2}{*}{ FAST } & $6.1 \pm 1.2$ \\
\hline & $\mathrm{HIGH}$ & & $6.4 \pm 1.0$ \\
\hline & NORMO & \multirow[t]{2}{*}{ SLOW } & $6.0 \pm 1.0$ \\
\hline & $\mathrm{HIGH}$ & & $6.5 \pm 0.6$ \\
\hline \multirow[t]{4}{*}{ RR (bpm) } & NORMO & \multirow[t]{2}{*}{ FAST } & $113 \pm 25$ \\
\hline & $\mathrm{HIGH}$ & & $104 \pm 38$ \\
\hline & NORMO & \multirow[t]{2}{*}{ SLOW } & $120 \pm 29$ \\
\hline & $\mathrm{HIGH}$ & & $100 \pm 24$ \\
\hline \multirow{4}{*}{$\mathrm{V}_{\mathrm{E}}^{\prime}(\mathrm{mL} / \mathrm{min})$} & NORMO & \multirow[t]{2}{*}{ FAST } & $202 \pm 28$ \\
\hline & $\mathrm{HIGH}$ & & $203 \pm 37$ \\
\hline & NORMO & \multirow[t]{2}{*}{ SLOW } & $206 \pm 17$ \\
\hline & $\mathrm{HIGH}$ & & $205 \pm 24$ \\
\hline \multirow[t]{4}{*}{ Ti/Ttot (s) } & NORMO & \multirow[t]{2}{*}{ FAST } & $0.4 \pm 0.1$ \\
\hline & $\mathrm{HIGH}$ & & $0.4 \pm 0.0$ \\
\hline & NORMO & \multirow[t]{2}{*}{ SLOW } & $0.3 \pm 0.0$ \\
\hline & $\mathrm{HIGH}$ & & $0.4 \pm 0.0$ \\
\hline \multirow{4}{*}{$\begin{array}{l}\text { Pplat, }_{\text {RS }} \\
\left(\mathrm{cmH}_{2} \mathrm{O}\right)\end{array}$} & NORMO & \multirow[t]{2}{*}{ FAST } & $13.3 \pm 4.7$ \\
\hline & $\mathrm{HIGH}$ & & $15.1 \pm 2.7$ \\
\hline & NORMO & \multirow[t]{2}{*}{ SLOW } & $10.7 \pm 1.2$ \\
\hline & $\mathrm{HIGH}$ & & $10.8 \pm 1.3^{*}$ \\
\hline \multirow{2}{*}{$\begin{array}{l}\Delta \mathrm{P}_{\mathrm{RS}} \\
\left(\mathrm{cmH}_{2} \mathrm{O}\right)\end{array}$} & NORMO & \multirow[t]{2}{*}{ FAST } & $9.9 \pm 2.9$ \\
\hline & $\mathrm{HIGH}$ & & $12.7 \pm 2.5$ \\
\hline
\end{tabular}

Values are means \pm SD of 7 animals/group. Respiratory variables obtained at FINAL. $V_{T}$, tidal volume; $\mathrm{RR}$, respiratory rate; $\mathrm{V}_{\mathrm{E}}$, minute ventilation; $\mathrm{Ti} / \mathrm{T}$ tot, ratio of inspiratory time to total time; $\mathrm{Pplat}{ }_{\mathrm{RS}}$, respiratory system plateau pressure; $\Delta \mathrm{P}_{\mathrm{RS}}$, respiratory system driving pressure. $\mathrm{NORMO}$ and $\mathrm{HIGH}$ : administration of Ringer lactate at $10 \mathrm{~mL} / \mathrm{kg} / \mathrm{h}$ and $30 \mathrm{~mL} / \mathrm{kg} / \mathrm{h}$, respectively. FAST: abrupt PEEP decrease from 9 to $3 \mathrm{cmH}_{2} \mathrm{O}$. SLOW: gradual PEEP decrease $\left(0.2 \mathrm{cmH}_{2} \mathrm{O} / \mathrm{min}\right)$ from 9 to $3 \mathrm{cmH}_{2} \mathrm{O}$.

* Significantly different from HIGH-FAST $(p<0.0125)$ 


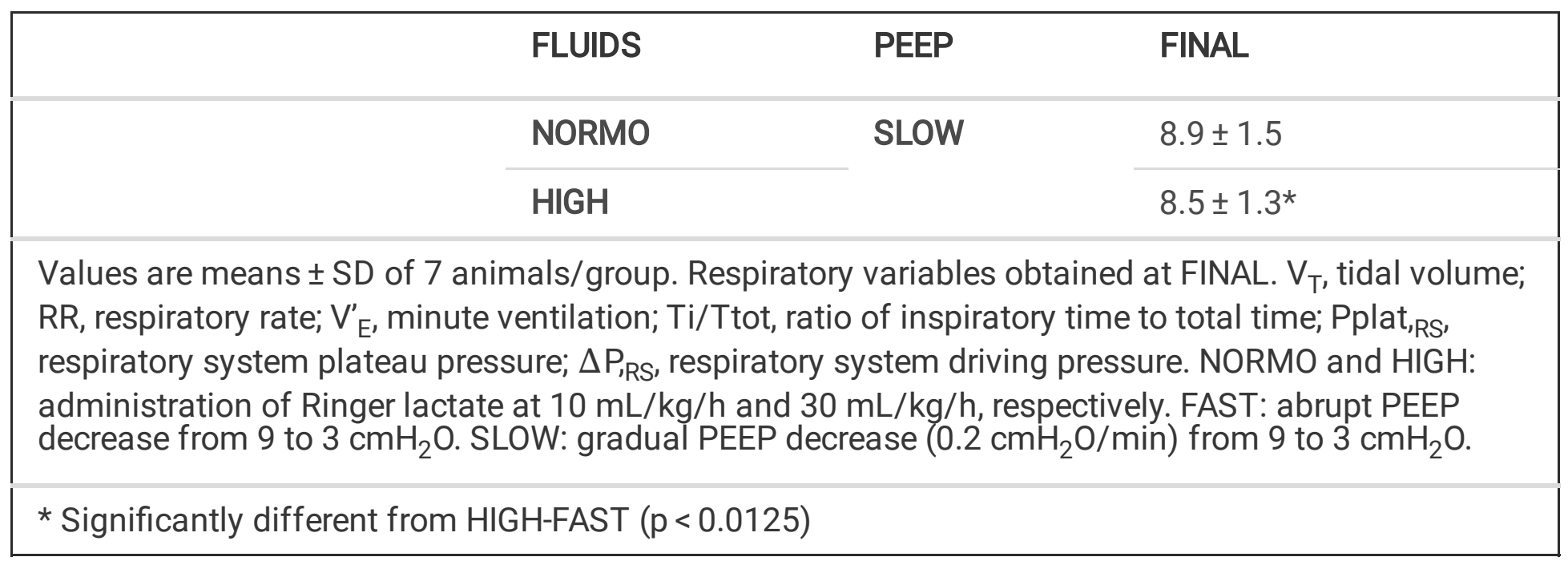

In animals treated with abrupt PEEP deflation, high fluid compared to standard fluid administration resulted in increased DAD score due to less interstitial edema, overdistension, and alveolar hemorrhage (Fig. 2). Abrupt compared with gradual PEEP deflation, when associated with high fluid administration, presented high DAD score due to reduced interstitial edema, overdistension, septal inflammation. No significant differences were observed in the degree of alveolar collapse among groups. Ultrastructural analysis of lung parenchyma showed greater interstitial edema in animals treated with high compared to standard fluid administration, independent of PEEP decrease rate. Basement membrane injury, extracellular matrix damage, type II epithelial dell damage, and endothelial cell damage scores were greater in the group treated with abrupt than gradual PEEP decrease, regardless of fluid status (Additional File 4, Table S4 and Fig. S1).

Abrupt PEEP decrease associated with high fluid administration led to increased gene expressions of IL-6, versican, syndecan-1, and VEGF. Under high fluid conditions, gradual PEEP decrease resulted in reduced IL-6 and VEGF. Gene expression of ZO-1 was greater in the group treated with standard fluid administration with gradual PEEP decrease compared to other groups, suggesting epithelial cell preservation. CC-16 was overexpressed in abrupt PEEP decrease groups, regardless of fluid status (Fig. 3).

High fluid administration induced higher kidney damage score (Fig. 4) and IL-6 expression (Fig. 5), independent of the rate of PEEP decrease. After abrupt PEEP decrease, interstitial edema, tubular cell vacuolization, deranged brush border in proximal tubular epithelia, and tubular cell desquamation (Fig. 4), as well as KIM-1, NGAL, and IL-6 gene expressions were higher in the high than in the standard fluid administration animals (Fig. 5). For the gradual PEEP decrease groups, KIM-1 expression was greater after high than standard fluid administration.

Concerning hemodynamic parameters, high fluid administration resulted in increased LV and RV areas, as well as RVCO, regardless of velocity of PEEP decrease (Table 2). Abrupt, compared to gradual PEEP decrease, reduced PAT/PET, independent of fluid status, suggesting higher pulmonary arterial pressures (Additional File 5, Fig. S2). 
Table 2

- Echocardiographic variables

\begin{tabular}{|c|c|c|c|}
\hline & FLUIDS & PEEP & \\
\hline \multirow{4}{*}{$\begin{array}{l}\text { LV area } \\
\left(\mathrm{cm}^{2}\right)\end{array}$} & NORMO & \multirow[t]{2}{*}{ FAST } & $0.20 \pm 0.04^{*}$ \\
\hline & $\mathrm{HIGH}$ & & $0.38 \pm 0.09$ \\
\hline & NORMO & \multirow[t]{2}{*}{ SLOW } & $0.18 \pm 0.07 \star \star$ \\
\hline & $\mathrm{HIGH}$ & & $0.30 \pm 0.08$ \\
\hline \multirow{4}{*}{$\begin{array}{l}\mathrm{RV} \text { area } \\
\left(\mathrm{cm}^{2}\right)\end{array}$} & NORMO & \multirow[t]{2}{*}{ FAST } & $0.29 \pm 0.03^{*}$ \\
\hline & $\mathrm{HIGH}$ & & $0.43 \pm 0.11$ \\
\hline & NORMO & \multirow[t]{2}{*}{ SLOW } & $0.30 \pm 0.05^{\star \star}$ \\
\hline & $\mathrm{HIGH}$ & & $0.34 \pm 0.03$ \\
\hline \multirow[t]{4}{*}{ RVCO (L/min) } & NORMO & \multirow[t]{2}{*}{ FAST } & $0.09 \pm 0.04^{*}$ \\
\hline & $\mathrm{HIGH}$ & & $0.19 \pm 0.07$ \\
\hline & NORMO & \multirow[t]{2}{*}{ SLOW } & $0.06 \pm 0.02^{\star \star}$ \\
\hline & $\mathrm{HIGH}$ & & $0.16 \pm 0.06$ \\
\hline \multirow[t]{4}{*}{ PAT/PET } & NORMO & \multirow[t]{2}{*}{ FAST } & $0.31 \pm 0.10$ \\
\hline & $\mathrm{HIGH}$ & & $0.34 \pm 0.10$ \\
\hline & NORMO & \multirow[t]{2}{*}{ SLOW } & $0.47 \pm 0.05 \#$ \\
\hline & $\mathrm{HIGH}$ & & $0.48 \pm 0.05^{\star}$ \\
\hline \multirow{4}{*}{$\begin{array}{l}\text { HR } \\
\text { (bpm) }\end{array}$} & NORMO & \multirow[t]{2}{*}{ FAST } & $330 \pm 85$ \\
\hline & $\mathrm{HIGH}$ & & $324 \pm 59$ \\
\hline & NORMO & \multirow[t]{2}{*}{ SLOW } & $339 \pm 31$ \\
\hline & $\mathrm{HIGH}$ & & $353 \pm 48$ \\
\hline \multicolumn{4}{|c|}{$\begin{array}{l}\text { Values are mean } \pm \mathrm{SD} \text { of } 7 \text { animals/group. Echocardiographic variables obtained at FINAL. LV, left } \\
\text { ventricle. RV, right ventricle. RVCO, right ventricular cardiac output. PAT, pulmonary acceleration time. } \\
\text { PET, pulmonary ejection time. PAT/PET ratio, indirect index of pulmonary arterial hypertension. HR, } \\
\text { heart rate (bpm). NORMO and HIGH: administration of Ringer lactate at } 10 \mathrm{~mL} / \mathrm{kg} / \mathrm{h} \text { and } 30 \mathrm{~mL} / \mathrm{kg} / \mathrm{h} \text {, } \\
\text { respectively. FAST: abrupt PEEP decrease from } 9 \text { to } 3 \mathrm{cmH}_{2} \mathrm{O} \text {. SLOW: gradual PEEP decrease }(0.2 \\
\left.\mathrm{cmH}_{2} \mathrm{O} / \mathrm{min}\right) \text { from } 9 \text { to } 3 \mathrm{cmH}_{2} \mathrm{O} \text {. }\end{array}$} \\
\hline \multicolumn{4}{|c|}{$\begin{array}{l}\text { *Significantly different from HIGH-FAST }(p<0.0125) \text {. \#Significantly different from NORMO-FAST- }(p< \\
0.0125) * * \text { Significantly different from HIGH-SLOW }(p<0.0125) \text {. }\end{array}$} \\
\hline
\end{tabular}


Consistent with our prior work with this pre-injury model that favored gradual as opposed to abrupt application of inflation pressures, gradual transitions appeared to be better tolerated on the deflation side as well. This relative advantage held consistently across a variety of histologic measures and biomarkers for both normal and high rates of fluid infusion and was accompanied by evidence of reduced cardiac and kidney impairment as well.

ARDS was induced by intratracheal instillation of endotoxin (first hit) [22]. This model reproduces several features of mild-moderate human ARDS, such as: impaired lung mechanics, atelectasis, damage to the alveolar-capillary membrane, and interstitial edema $[13,23]$. Only male Wistar rats were used to avoid any cyclic influence of female hormones on molecular biology analyses. Animals were then randomized to receive different mechanical ventilation strategies and fluids as a second hit. Among the crystalloids, Ringer's lactate was chosen since it avoids hyperchloremic acidosis that predictably accompanies the use of saline [24]. The high rate of fluid infusion was pro-rated on the upper limit adopted by the Surviving Sepsis Campaign [25] and based on previous pilot studies in endotoxin induced lung injury animals treated with different mechanical ventilation strategies as well standard and high fluid administration. Along this line, the volume of fluids of $7 \mathrm{ml}$ versus $16 \mathrm{ml}$ at FINAL kept the MAP above $70 \mathrm{mmHg}$ in our rats. The relative volume of fluids administered in rats differs from humans due to differences in lung pulmonary vessels (anatomy, size, and number of vessels). At the end of the experiment (FINAL), left and right ventricular areas, as well as cardiac outputs, were greater in high compared to standard fluid administration groups. The initial PEEP level $\left(9 \mathrm{cmH}_{2} \mathrm{O}\right)$ was sufficient to keep the lungs fully open [13] and the animals alive during $1 \mathrm{~h}$. Moreover, this PEEP level resembles that used in mechanically ventilated critical care patients $\left(18 \mathrm{cmH}_{2} \mathrm{O}\right)$, taking into account differences in transpulmonary pressures between humans and rats [26]. We abruptly decreased PEEP level across a pressure range that paralleled but did not match that of a previous study in rabbits [9]. Such decompressions may happen in practice during aggressive weaning or during accidental or intentional mechanical ventilator disconnection. $\mathrm{PEEP}=9 \mathrm{cmH}_{2} \mathrm{O}$ was applied for $30 \mathrm{~min}$ since, as based on previous pilot studies, it opens alveoli and keeps them homogeneously open. The lung biomarkers measured in this study are related to increased inflammation (IL-6) [27], extracellular matrix damage (versican, syndecan) [28], endothelial cell injury (VEGF) [29], and tight junction integrity (ZO-1) [30]. The selected kidney biomarkers (KIM-1 and NGAL) are associated with renal proximal tubular injury [31] and severity of kidney disease [32].

In investigations of VILI mechanisms and outcomes, ample attention has been directed to the events of inflation, with the result of markedly improving our understanding of this component of the injury process. Recent studies, however, indicate that the neglected deflation side of tidal pressure withdrawal deserves closer scrutiny [9]. The linkage of excessive strain, inflation energy, and cycling frequency with VILI is rather well established [33]. Yet, the parenchyma also absorbs some of the potential energy stored at end-inspiration, experiencing additional strains during the early part of deflation as the lung refolds and rearranges into its (proto-inspiratory) position. Experimental and clinical evidence provided by several groups suggests that slowing early expiration and regulating expiratory flow may reduce lung injury [34, 
35]. While the exact mechanism underlying these intriguing and consistent observations remains obscure, the tacit inference has been that the explanation would center on the magnitude and distribution of the released parenchymal energy. That tissue energy load may influence both the airspace and vascular compartments.

Like the expiratory portion of the tidal cycle, the influence of vascular events has received relatively little consideration. The potential for very high capillary pressures and flows to cause stress fractures of the alveolar-capillary barrier provides a compelling explanation for the parenchymal hemorrhage that accompanies certain forms of cardiogenic pulmonary edema and the high cardiac output conditions of extreme athletic stress. A series of prior studies from one of our own groups demonstrated that the presence of high microvascular pressure gradients and flows may be an essential determinant of overt VILI expression for lungs ventilated with identical airspace and left atrial (pulmonary venous) pressures $[2,3]$. The clear structural damage and endothelial damage that occurs in that setting may theoretically result (at least in part) from unmeasured shearing forces and energy released by blood flowing through a compressed and restricted vascular bed. Here, we showed that gradually decreasing the PEEP level promotes lung and kidney protection. We may infer that abruptly decreasing PEEP through a wide range may lead to profound hemodynamic changes as blood shifts from peripheral toward central vessels. If so, pulmonary endothelial cells and extracellular matrix are likely subjected to major biophysical challenges, such as supra-physiological shear stress [36]. Endothelial cells have a variety of receptors, which sense flow and transmit mechanical signals through mechanosensitive signaling pathways to recipient molecules that lead to phenotypic and functional changes [37]. IL-6, versican, syndecan, and VEGF gene expressions in these experiments corroborate this hypothesis. VEGF, in conjunction with its receptor VEGFR2, has been shown to participate in the transmission of forces to intercellular junction protein complexes (VE-cadherin, $\beta$-catenin, and phosphatidylinositol 3 kinase to phosphorylate Akt and PECAM-1) [29]. On the other hand, the most protective strategy, namely NORMO-SLOW, led to high expression of ZO-1, which enhances endothelial bonding, impeding plasma leakage from vascular to alveolar spaces. Alternatively, altered perfusion might, in concept, influence the mechanical properties of the parenchyma sufficiently to accentuate micromechanical stresses during either half of the tidal cycle.

Present-day clinical practice tends to apply stereotyped, rapidly rising and falling flow profiles during mechanical ventilation, which are quite unlike spontaneous breathing in healthy lungs. Such profiles make changes without the gradual transition characteristic of natural rhythms. Few studies of VILI have been directed at the rate of ascent or descent of changing pressures (abruptly or slowly) over multiple tidal cycles across the same driving pressure or PEEP increment. Katira and colleagues [9] demonstrated the potential for an abrupt release of high-level PEEP to inflict lung injury, a result the authors attributed to mismatching of left ventricular preload and afterload, with the lungs affected secondarily. In prior work by our group, we have demonstrated that gradual application of recruitment maneuvers favors tolerance to that intervention in the same rodent model of ARDS we used in this study [7, 8]. We have also reported that increasing $V_{T}$ gradually over multiple breathing cycles provokes less lung injury than when the 
transition to the same maximum $\mathrm{V}_{\mathrm{T}}$ is imposed abruptly, despite the delivery of a significantly greater cumulative load of inflating energy [5].

Data from the present study indicate that increased lung tissue damage results from an abrupt rather than a gradual PEEP release, in the presence of an increased rate of fluid infusion. Abrupt transitioning caused the lung to experience histologic and molecular evidence of inflammation and endothelial trauma, which was not explained by the left ventricular loading mismatch reported by Katira and colleagues [9]. The differences between our findings may be related to the duration of high PEEP application, the nature of the model (healthy rabbits vs. pre-injured rats), or the magnitude of the sudden release to ZEEP (vs. 3 $\mathrm{cmH}_{2} \mathrm{O}$ ). Rather, in our study the lung and right ventricle were adversely affected, whereas the echocardiographic ejection pattern of the left ventricle was not. Fluid loading produced the expected changes of tissue edema but affected the nature or severity of lung injury only inconsistently.

It must be noted that the mean airway pressures in the animals treated with gradual PEEP decrease were somewhat higher than those in the abrupt PEEP decrease because of the intentional lingering of PEEP above the baseline value. One possibility to consider is that gradual decline may have promoted stress adaptation and more even distribution of parenchymal strain. Simultaneously, however, higher mean airway pressure might be expected to have increased pulmonary arterial resistance, adversely affecting the right ventricle-opposite to our actual findings. The validity of such speculations regarding benefit of slower PEEP release, however, remains untested.

Kidney damage caused by endotoxin [18] is particularly sensitive to venous congestion. In this context, fluid overload can result in severe and sustained kidney injury [38]. In the current model, acute kidney injury score and gene expression of kidney injury molecule-1 were greater in high compared to standard rate of fluid administration in both abrupt and gradual PEEP decrease groups. One possibility is that differences in mechanotransduction induced by abrupt or gradual PEEP removal may yield less kidney damage than fluid increase itself. In fact, high rates of Ringer's lactate administration appear to potentiate kidney damage, by an as yet unconfirmed mechanism [39].

\section{Possible Clinical Implications}

In ARDS, high PEEP associated with low tidal volume has been associated with reduced venous return, cardiac output and pulmonary capillary inflow, while simultaneously increasing extravascular pressure. Consequently, lung edema may decline even in the presence of alveolar capillary damage [40]. During PEEP removal, hemodynamic instability and increased edema may occur, and often presenting a challenge to correctly managing the amount of fluids to be administered. According to our study results:

1) PEEP should be reduced gradually, regardless of the amount of fluid administered, to avoid increasing pulmonary arterial hypertension; 2) Abrupt PEEP decreases in conjunction with high fluid therapy may promote lung inflammation and vascular damage; 3 ) Gradually reducing PEEP in association with standard fluid administration helps preserve the epithelium from further damage; and 4) To hinder kidney damage, high amounts of fluid should be avoided, regardless of the velocity of PEEP deflation. Data from 
rodent experiments afford only mechanistic insights into VILI and cannot be directly applied to clinical settings without reservation. Even though abrupt deflation (from 9 to $3 \mathrm{cmH} 2 \mathrm{O}$ in rats, approximating 18 to $6 \mathrm{cmH} 20$ in humans) does not occur commonly in clinical practice, these data provide a proof of concept that ventilator-induced lung injury is influenced by interaction between the pace of PEEP decreases and amount of fluids administered.

\section{Limitations}

Some limitations of the present study must be acknowledged. Experiments were conducted in a smallanimal model of mild-moderate ARDS and tested only one $\mathrm{V}_{\mathrm{T}}$ and minute ventilation. These findings apply to these specific experimental circumstances and time intervals. The selected PEEP levels chosen for the PEEP transition were arbitrarily selected; $9 \mathrm{cmH}_{2} \mathrm{O}$ approaches the upper limit of what rats can sustain for the intended duration of these experiments without life-threatening hemodynamic compromise, whereas $3 \mathrm{cmH}_{2} \mathrm{O}$ is a well-tolerated level that may afford some level of lung protection against ventilation stress. The observation time was $1 \mathrm{~h}$ in order to avoid hemodynamic impairment, which might have introduced bias into our study. Accordingly, we did not assess protein levels of biological markers. However, this duration of mechanical ventilation was sufficient for gene expression of key markers of interest [13]. Echocardiography was performed 10 minutes after deflation, and thus we cannot rule out that a right to left ventricular mismatch may have occurred during or immediately after PEEP reduction.

\section{Conclusions}

In the current model of mild-moderate ARDS, decreasing PEEP abruptly increased pulmonary arterial hypertension under background conditions of standard and high fluid administration. The combination of abrupt PEEP decrease and high fluid administration led to greater lung and kidney injury, inflammation and endothelial cell damage. This information adds to the growing body of evidence that supports gradual transitioning of ventilatory patterns and warrants directing additional investigative effort into vascular and deflation issues that impact lung protection.

\section{Declarations}

\section{Ethics approval}

This study was approved by the Animal Care Committee of the Health Sciences Centre, Federal University of Rio de Janeiro (CEUA: 122/18).

\section{Consent for publication}

Not applicable

\section{Availability of data and materials}


The datasets used and/or analyzed during the present study are available from the corresponding author on reasonable request.

\section{Competing interests}

None reported

\section{Funding}

Supported by the Brazilian Council for Scientific and Technological Development (CNPq; Brasília, Brazil), the Rio de Janeiro State Research Foundation (FAPERJ; Rio de Janeiro, Brazil), the São Paulo State Research Foundation (FAPESP; São Paulo, Brazil), the National Institute of Science and Technology for Regenerative Medicine (INCT-REGENERA; Rio de Janeiro, Brazil), and the Coordination for the Improvement of Higher Education Personnel (CAPES; Brasília, Brazil).

\section{Authors' contributions}

NNR, PLS, JJM, PP, PRMR participated in the design of the study, performed data analyses, and write the manuscript; CSS, MAA, MVO, PSS, VLC, and FFC performed the analyses. All authors read and approved the final manuscript.

\section{Acknowledgements}

The authors express our gratitude to Andre Benedito da Silva, B.Sc., Laboratory of Pulmonary Investigation, Carlos Chagas Filho Biophysics Institute, Federal University of Rio de Janeiro, Rio de Janeiro, Brazil, for animal care; Arlete Fernandes, B.Sc., Laboratory of Pulmonary Investigation, Carlos Chagas Filho Biophysics Institute, Federal University of Rio de Janeiro, Rio de Janeiro, Brazil, for her help with microscopy; Maíra Rezende Lima, M.Sc., Laboratory of Pulmonary Investigation, Carlos Chagas Filho Biophysics Institute, Federal University of Rio de Janeiro, Rio de Janeiro, Brazil, for her assistance in molecular biology analysis; Moira Elizabeth Shottler, B.A., Rio de Janeiro, Brazil, and Filippe Vasconcellos, B.A., São Paulo, Brazil, for their assistance in editing the manuscript; Ronir Raggio Luiz, Ph.D., Institute of Public Health Studies, Federal University of Rio de Janeiro, Rio de Janeiro, Brazil, for his help with statistics; and Dräger Medical, Lübeck, Germany, for technical support.

\section{Abbreviations}

ARDS: acute respiratory distress syndrome, CC-16: club cell protein 16, DAD: diffuse alveolar damage; $\mathrm{FiO}_{2}$ : fraction of inspired oxygen; HR: Heart Rate; IL: interleukin, KIM: kidney injury molecule; LPS: lipopolysaccharide; LV: left ventricle; MAP: Mean Arterial Pressure; NGAL: neutrophil gelatinase associated lipocalin; NV: Non-ventilated; PAT: pulmonary acceleration time; PEEP: positive end expiratory pressure; $\mathrm{PET}$ : pulmonary ejection time; $\mathrm{Pplat}{ }_{\mathrm{RS}}$ : respiratory system plateau pressure; RR: respiratory rate; RT-PCR: Quantitative real-time reverse transcription polymerase chain reaction; RV: right ventricle; RVCO: right ventricular cardiac output; Ti/Ttot: Inspiratory time divided by duty cycle; $\mathrm{V}_{\mathrm{E}}^{\prime}$ : minute ventilation; 
VCV: volume-controlled mode; VEGF: vascular endothelial growth factor; VILI: ventilator induced lung injury; $\mathrm{V}_{\mathrm{T}}$ : Tidal volume; ZEEP: zero end-expiratory pressure; ZO-1: zona occludens-1; DP, ${ }_{\mathrm{RS}}$ : respiratory system driving pressure.

\section{References}

1. Marini JJ, Gattinoni L: Protecting the Ventilated Lung: Vascular Surge and Deflation Energetics. Am J Respir Crit Care Med 2018; 198(9):1112-1114. http://www.ncbi.nlm.nih.gov/pubmed/29966100.

2. Broccard AF, Hotchkiss JR, Kuwayama N, Olson DA, Jamal S, Wangensteen DO et al: Consequences of vascular flow on lung injury induced by mechanical ventilation. Am J Respir Crit Care Med 1998; 157(6 Pt 1):1935-1942. http://www.ncbi.nlm.nih.gov/pubmed/9620930.

3. Hotchkiss JR, Jr., Blanch L, Murias G, Adams AB, Olson DA, Wangensteen OD et al: Effects of decreased respiratory frequency on ventilator-induced lung injury. Am J Respir Crit Care Med 2000; 161(2 Pt 1):463-468. http://www.ncbi.nlm.nih.gov/pubmed/10673186.

4. van Mourik N, Metske HA, Hofstra JJ, Binnekade JM, Geerts BF, Schultz MJ et al: Cumulative fluid balance predicts mortality and increases time on mechanical ventilation in ARDS patients: An observational cohort study. PLoS One 2019; 14(10):e0224563. http://www.ncbi.nlm.nih.gov/pubmed/31665179.

5. Felix NS, Samary CS, Cruz FF, Rocha NN, Fernandes MVS, Machado JA et al: Gradually Increasing Tidal Volume May Mitigate Experimental Lung Injury in Rats. Anesthesiology 2019; 130(5):767-777. http://www.ncbi.nIm.nih.gov/pubmed/30870161.

6. Lim SC, Adams AB, Simonson DA, Dries DJ, Broccard AF, Hotchkiss JR et al: Transient hemodynamic effects of recruitment maneuvers in three experimental models of acute lung injury. Crit Care Med 2004; 32(12):2378-2384. http://www.ncbi.nlm.nih.gov/pubmed/15599139.

7. Silva PL, Moraes L, Santos RS, Samary C, Ornellas DS, Maron-Gutierrez T et al: Impact of pressure profile and duration of recruitment maneuvers on morphofunctional and biochemical variables in experimental lung injury. Crit Care Med 2011;39(5):1074-1081.

http://www.ncbi.nlm.nih.gov/pubmed/21263326.

8. Silva PL, Moraes L, Santos RS, Samary C, Ramos MB, Santos CL et al: Recruitment maneuvers modulate epithelial and endothelial cell response according to acute lung injury etiology. Crit Care Med 2013; 41(10):e256-265. http://www.ncbi.nlm.nih.gov/pubmed/23887231.

9. Katira BH, Engelberts D, Otulakowski G, Giesinger RE, Yoshida T, Post M et al: Abrupt Deflation after Sustained Inflation Causes Lung Injury. Am J Respir Crit Care Med 2018; 198(9):1165-1176. http://www.ncbi.nlm.nih.gov/pubmed/29902384.

10. Prewitt RM, McCarthy J, Wood LD: Treatment of acute low pressure pulmonary edema in dogs: relative effects of hydrostatic and oncotic pressure, nitroprusside, and positive end-expiratory pressure. J Clin Invest 1981; 67(2):409-418. http://www.ncbi.nlm.nih.gov/pubmed/7007436. 
11. Wiedemann HP, Wheeler AP, Bernard GR, Thompson BT, Hayden D, deBoisblanc B et al: Comparison of two fluid-management strategies in acute lung injury. N Engl J Med 2006; 354(24):2564-2575. http://www.ncbi.nIm.nih.gov/pubmed/16714767.

12. Kuebler WM, Ying X, Singh B, Issekutz AC, Bhattacharya J: Pressure is proinflammatory in lung venular capillaries. J Clin Invest 1999; 104(4):495-502.

http://www.ncbi.nlm.nih.gov/pubmed/10449441.

13. Samary CS, Santos RS, Santos CL, Felix NS, Bentes M, Barboza T et al: Biological Impact of Transpulmonary Driving Pressure in Experimental Acute Respiratory Distress Syndrome. Anesthesiology 2015; 123(2):423-433. http://www.ncbi.nlm.nih.gov/pubmed/26039328.

14. Spieth PM, Silva PL, Garcia CS, Ornellas DS, Samary CS, Moraes L et al: Modulation of stress versus time product during mechanical ventilation influences inflammation as well as alveolar epithelial and endothelial response in rats. Anesthesiology 2015; 122(1):106-116. http://www.ncbi.nlm.nih.gov/pubmed/25141026.

15. Lang RM, Badano LP, Mor-Avi V, Afilalo J, Armstrong A, Ernande L et al: Recommendations for cardiac chamber quantification by echocardiography in adults: an update from the American Society of Echocardiography and the European Association of Cardiovascular Imaging. J Am Soc Echocardiogr 2015; 28(1):1-39 e14. http://www.ncbi.nlm.nih.gov/pubmed/25559473.

16. Thibault HB, Kurtz B, Raher MJ, Shaik RS, Waxman A, Derumeaux G et al: Noninvasive assessment of murine pulmonary arterial pressure: validation and application to models of pulmonary hypertension. Circ Cardiovasc Imaging 2010; 3(2):157-163. http://www.ncbi.nlm.nih.gov/pubmed/20044514.

17. Uhlig C, Silva PL, Ornellas D, Santos RS, Miranda PJ, Spieth PM et al: The effects of salbutamol on epithelial ion channels depend on the etiology of acute respiratory distress syndrome but not the route of administration. Respir Res 2014; 15:56. http://www.ncbi.nlm.nih.gov/pubmed/24886221.

18. Mendes RS, Oliveira MV, Padilha GA, Rocha NN, Santos CL, Maia LA et al: Effects of crystalloid, hyper-oncotic albumin, and iso-oncotic albumin on lung and kidney damage in experimental acute lung injury. Respir Res 2019; 20(1):155. http://www.ncbi.nlm.nih.gov/pubmed/31311539.

19. Silva PL, Cruz FF, Samary CDS, Moraes L, de Magalhaes RF, Fernandes MVS et al: Biological Response to Time-Controlled Adaptive Ventilation Depends on Acute Respiratory Distress Syndrome Etiology. Crit Care Med 2018; 46(6):e609-e617. http://www.ncbi.nIm.nih.gov/pubmed/29485489.

20. Akamine R, Yamamoto T, Watanabe M, Yamazaki N, Kataoka M, Ishikawa M et al: Usefulness of the 5 region of the cDNA encoding acidic ribosomal phosphoprotein P0 conserved among rats, mice, and humans as a standard probe for gene expression analysis in different tissues and animal species. J Biochem Biophys Methods 2007; 70(3):481-486. http://www.ncbi.nlm.nih.gov/pubmed/17196660.

21. Schmittgen TD, Livak KJ: Analyzing real-time PCR data by the comparative $C(T)$ method. Nat Protoc 2008; 3(6):1101-1108. http://www.ncbi.nlm.nih.gov/pubmed/18546601. 
22. Matute-Bello G, Downey G, Moore BB, Groshong SD, Matthay MA, Slutsky AS et al: An official American Thoracic Society workshop report: features and measurements of experimental acute lung injury in animals. Am J Respir Cell Mol Biol 2011; 44(5):725-738. http://www.ncbi.nlm.nih.gov/pubmed/21531958.

23. Riva DR, Oliveira MB, Rzezinski AF, Rangel G, Capelozzi VL, Zin WA et al: Recruitment maneuver in pulmonary and extrapulmonary experimental acute lung injury. Crit Care Med 2008; 36(6):1900-1908. http://www.ncbi.nlm.nih.gov/pubmed/18496360.

24. O'Malley CM, Frumento RJ, Hardy MA, Benvenisty Al, Brentjens TE, Mercer JS et al: A randomized, double-blind comparison of lactated Ringer's solution and $0.9 \% \mathrm{NaCl}$ during renal transplantation. Anesth Analg 2005; 100(5):1518-1524, table of contents. http://www.ncbi.nlm.nih.gov/pubmed/15845718.

25. Rhodes A, Evans LE, Alhazzani W, Levy MM, Antonelli M, Ferrer R et al: Surviving Sepsis Campaign: International Guidelines for Management of Sepsis and Septic Shock: 2016. Crit Care Med 2017; 45(3):486-552. http://www.ncbi.nlm.nih.gov/pubmed/28098591.

26. Caironi P, Langer T, Carlesso E, Protti A, Gattinoni L: Time to generate ventilator-induced lung injury among mammals with healthy lungs: a unifying hypothesis. Intensive Care Med 2011; 37(12):19131920. http://www.ncbi.nlm.nih.gov/pubmed/22052185.

27. Cross LJ, Matthay MA: Biomarkers in acute lung injury: insights into the pathogenesis of acute lung injury. Crit Care Clin 2011; 27(2):355-377. http://www.ncbi.nlm.nih.gov/pubmed/21440206.

28. Kang I, Chang MY, Wight TN, Frevert CW: Proteoglycans as Immunomodulators of the Innate Immune Response to Lung Infection. J Histochem Cytochem 2018; 66(4):241-259. http://www.ncbi.nlm.nih.gov/pubmed/29328866.

29. Fujiwara K, Masuda M, Osawa M, Kano Y, Katoh K: Is PECAM-1 a mechanoresponsive molecule? Cell Struct Funct 2001; 26(1):11-17. http://www.ncbi.nlm.nih.gov/pubmed/11345499.

30. Van Itallie CM, Fanning AS, Bridges A, Anderson JM: ZO-1 stabilizes the tight junction solute barrier through coupling to the perijunctional cytoskeleton. Mol Biol Cell 2009; 20(17):3930-3940. http://www.ncbi.nlm.nih.gov/pubmed/19605556.

31. Han WK, Bailly V, Abichandani R, Thadhani R, Bonventre JV: Kidney Injury Molecule-1 (KIM-1): a novel biomarker for human renal proximal tubule injury. Kidney Int 2002; 62(1):237-244. http://www.ncbi.nlm.nih.gov/pubmed/12081583.

32. Khawaja S, Jafri L, Siddiqui I, Hashmi M, Ghani F: The utility of neutrophil gelatinase-associated Lipocalin (NGAL) as a marker of acute kidney injury (AKI) in critically ill patients. Biomark Res 2019; 7:4. http://www.ncbi.nlm.nih.gov/pubmed/30834123.

33. Marini JJ, Rocco PRM, Gattinoni L: Static and Dynamic Contributors to Ventilator-induced Lung Injury in Clinical Practice. Pressure, Energy, and Power. Am J Respir Crit Care Med 2020; 201(7):767774. http://www.ncbi.nlm.nih.gov/pubmed/31665612.

34. Koutsoukou A, Pecchiari M: Expiratory flow-limitation in mechanically ventilated patients: A risk for ventilator-induced lung injury? World J Crit Care Med 2019; 8(1):1-8. 
http://www.ncbi.nlm.nih.gov/pubmed/30697515.

35. Schmidt J, Wenzel C, Spassov S, Borgmann S, Lin Z, Wollborn J et al: Flow-Controlled Ventilation Attenuates Lung Injury in a Porcine Model of Acute Respiratory Distress Syndrome: A Preclinical Randomized Controlled Study. Crit Care Med 2020; 48(3):e241-e248. http://www.ncbi.nlm.nih.gov/pubmed/31856000.

36. Davies PF: Hemodynamic shear stress and the endothelium in cardiovascular pathophysiology. Nat Clin Pract Cardiovasc Med 2009; 6(1):16-26. http://www.ncbi.nlm.nih.gov/pubmed/19029993.

37. Chistiakov DA, Orekhov AN, Bobryshev YV: Effects of shear stress on endothelial cells: go with the flow. Acta Physiol (Oxf) 2017; 219(2):382-408. http://www.ncbi.nlm.nih.gov/pubmed/27246807.

38. Ding X, Cheng Z, Qian Q: Intravenous Fluids and Acute Kidney Injury. Blood Purif 2017; 43(1-3):163172. http://www.ncbi.nlm.nih.gov/pubmed/28114128.

39. Silva PL, Cruz FF, Fujisaki LC, Oliveira GP, Samary CS, Ornellas DS et al: Hypervolemia induces and potentiates lung damage after recruitment maneuver in a model of sepsis-induced acute lung injury. Crit Care 2010; 14(3):R114. http://www.ncbi.nlm.nih.gov/pubmed/20546573.

40. Zabner J, Angeli LS, Martinez RR, Sanchez de Leon R: The effects of graded administration of positive end expiratory pressure on the fluid filtration rate in isolated rabbit lungs, using normal lungs, hydrostatic oedema lungs and oleic acid induced oedema. Intensive Care Med 1990; 16(2):8994. http://www.ncbi.nlm.nih.gov/pubmed/2185291.

\section{Figures}




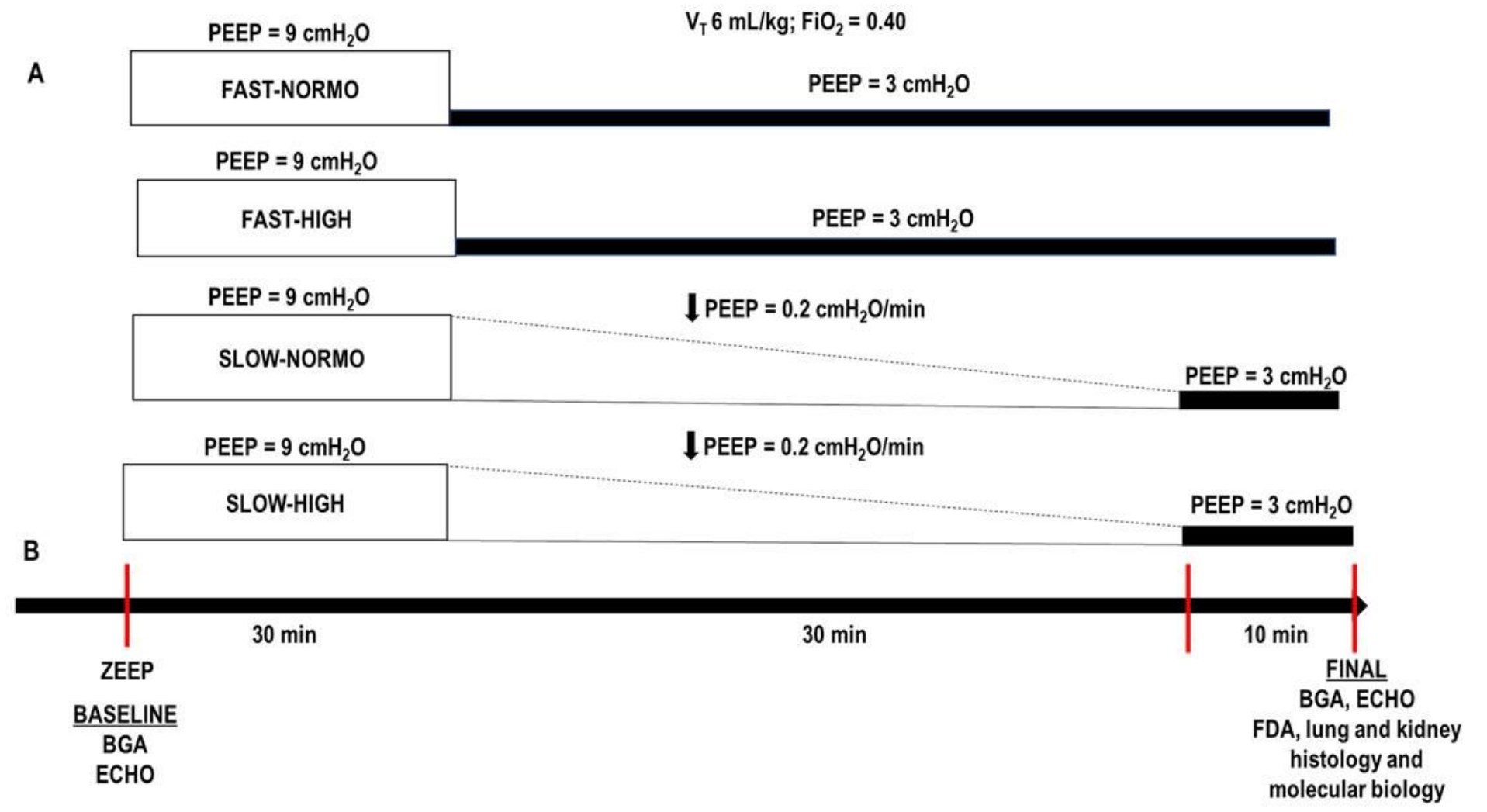

Figure 1

Protocol (A) and timeline representation of the experimental protocol (B). Arterial blood gases and echocardiography were evaluated at BASELINE and FINAL. BGA, blood gas analysis; ECHO, echocardiography; FDA, functional data acquisition; FiO2, fraction of inspired oxygen; ZEEP, zero endexpiratory pressure; PEEP, positive end-expiratory pressure; VT, tidal volume. Twenty-four hours after intratracheal administration of Escherichia coli lipopolysaccharide, rats received standard $[10 \mathrm{~mL} / \mathrm{kg} / \mathrm{h}$ (NORMO)] or high [30 mL/kg/h (HIGH)] volume of Ringer's lactate. For $30 \mathrm{~min}$, all rats, regardless of fluid status, were mechanically ventilated with $\mathrm{VT}=6 \mathrm{~mL} / \mathrm{kg}$ and PEEP $=9 \mathrm{cmH} 2 \mathrm{O}$, and then randomized to the following groups: abrupt PEEP decrease from 9 to $3 \mathrm{cmH} 2 \mathrm{O}$ (FAST) or gradual PEEP decrease $(0.2$ $\mathrm{cmH} 2 \mathrm{O} / \mathrm{min}$ ) from 9 to $3 \mathrm{cmH} 2 \mathrm{O}$ (SLOW) for $30 \mathrm{~min}$. 
A

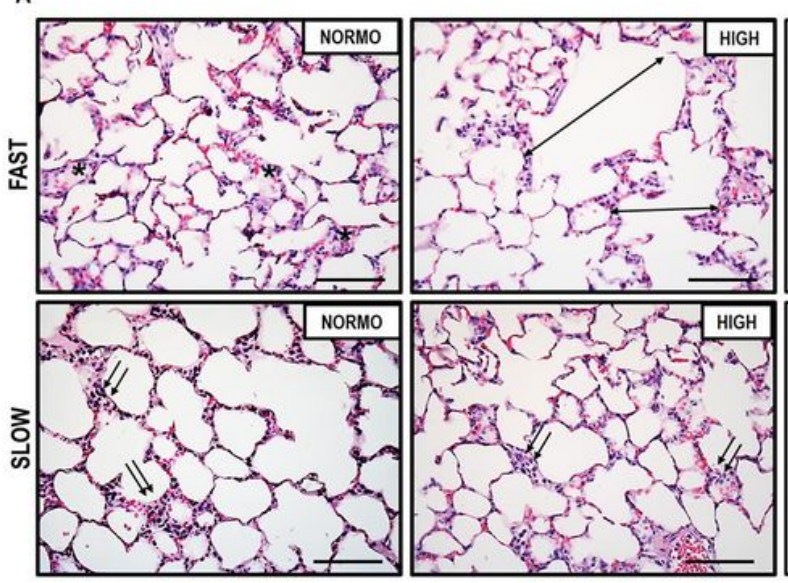

B
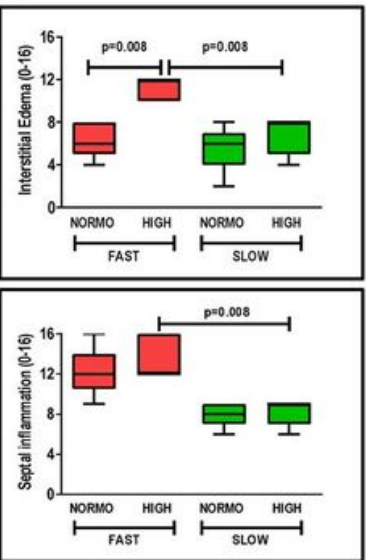
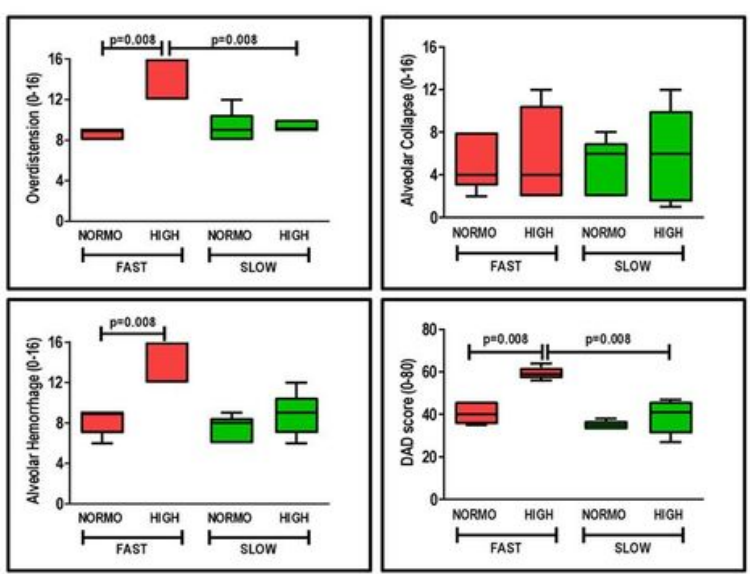

Figure 2

A: Representative photomicrographs (light microscopy) of lung parenchyma stained with hematoxylin and eosin. Photomicrographs are representative of data obtained from lung sections of 7 animals (original magnification, $\times 400$ ). Bars $=100 \mu \mathrm{m}$. Note the presence of interstitial edema (asterisk), lung overdistension (double arrows), and alveolar-capillary damage (presence of neutrophils and erythrocytes in the alveolar septa) (two arrows). B: Diffuse alveolar damage (DAD) score; scores arithmetically averaged from two independent investigators representing injury from interstitial edema, overdistension, alveolar collapse, septal inflammation, and alveolar hemorrhage. Boxes show the interquartile (25 to $75 \%$ ) range, whiskers encompass the range (minimum to maximum), and horizontal lines represent median values of seven animals/group. Rats received standard [10 mL/kg/h (NORMO)] or high [30 $\mathrm{mL} / \mathrm{kg} / \mathrm{h}$ (HIGH)] volume of Ringer's lactate. FAST: abrupt PEEP decrease from 9 to $3 \mathrm{cmH} 2 \mathrm{O}$. SLOW: gradual PEEP decrease $(0.2 \mathrm{cmH} 2 \mathrm{O} / \mathrm{min})$ from 9 to $3 \mathrm{cmH} 2 \mathrm{O}$. 

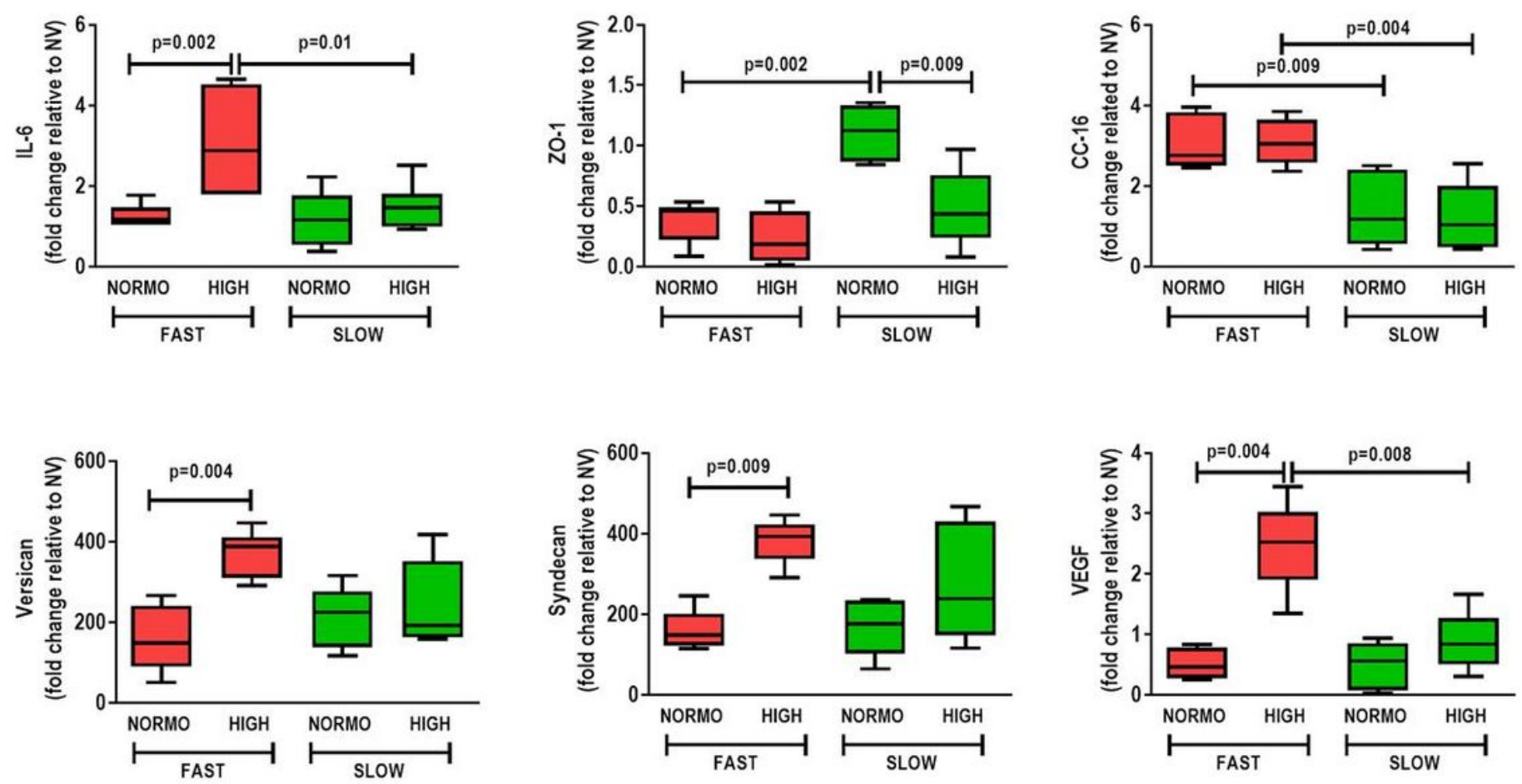

\section{Figure 3}

Expression of biologic markers associated with inflammation [interleukin (IL)-6), tight junctions [zonula occludens (ZO)-1], epithelial cell damage [club cell protein (CC)-16], extracellular matrix remodeling (versican, syndecan-1), and endothelial cell damage [(vascular endothelial growth factor (VEGF)]. Relative gene expression was calculated as a ratio of the average gene expression levels compared with the reference gene (acidic ribosomal phosphoprotein P0, 36B4) and expressed as fold change relative to nonventilated animals (NV). Boxes show the interquartile (25 to $75 \%$ ) range, whiskers encompass the range (minimum to maximum), and horizontal lines represent median values of 7 animals/group. Rats received standard [10 mL/kg/h (NORMO)] or high [30 mL/kg/h (HIGH)] volume of Ringer's lactate. FAST: abrupt PEEP decrease from 9 to $3 \mathrm{cmH} 20$. SLOW: gradual PEEP decrease $(0.2 \mathrm{cmH} 2 \mathrm{O} / \mathrm{min})$ from 9 to $3 \mathrm{cmH} 20$.

A
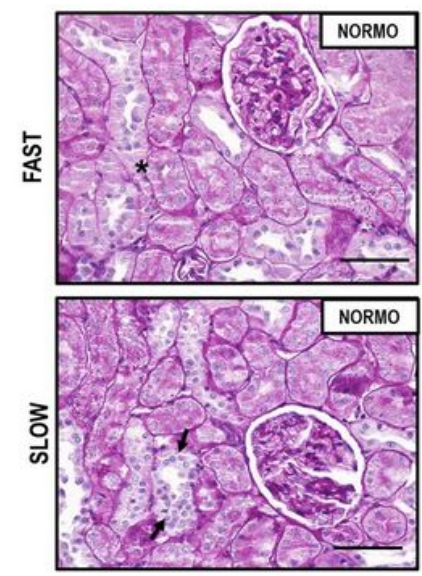
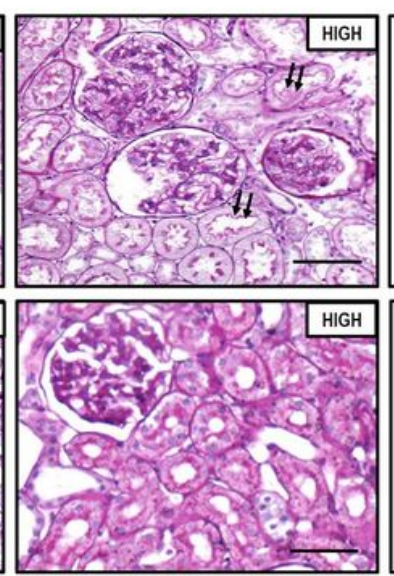

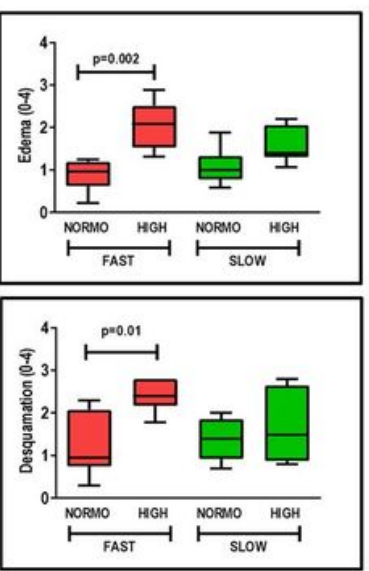

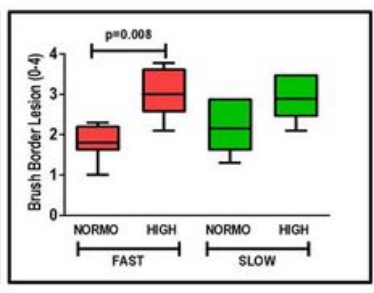

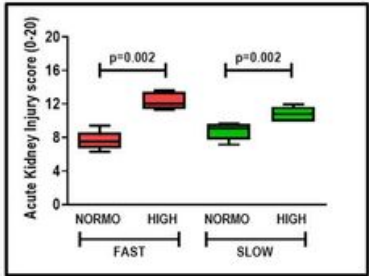




\section{Figure 4}

A: Representative photomicrographs (light microscopy) of kidney parenchyma stained with hematoxylin and eosin. Photomicrographs are representative of data obtained from kidney sections of 7 animals (original magnification, $\times 400$ ). Bars $=100 \mu \mathrm{m}$. Note the presence of interstitial edema (asterisk), brush border lesion (two arrows), and cellular desquamation (one arrow). B: Kidney injury score; scores arithmetically averaged from two independent investigators representing injury from interstitial edema, vacuolization, brush border lesion, desquamation, and inflammation are shown. Boxes show the interquartile ( 25 to $75 \%$ ) range, whiskers encompass the range (minimum to maximum), and horizontal lines represent median values of 7 animals/group.
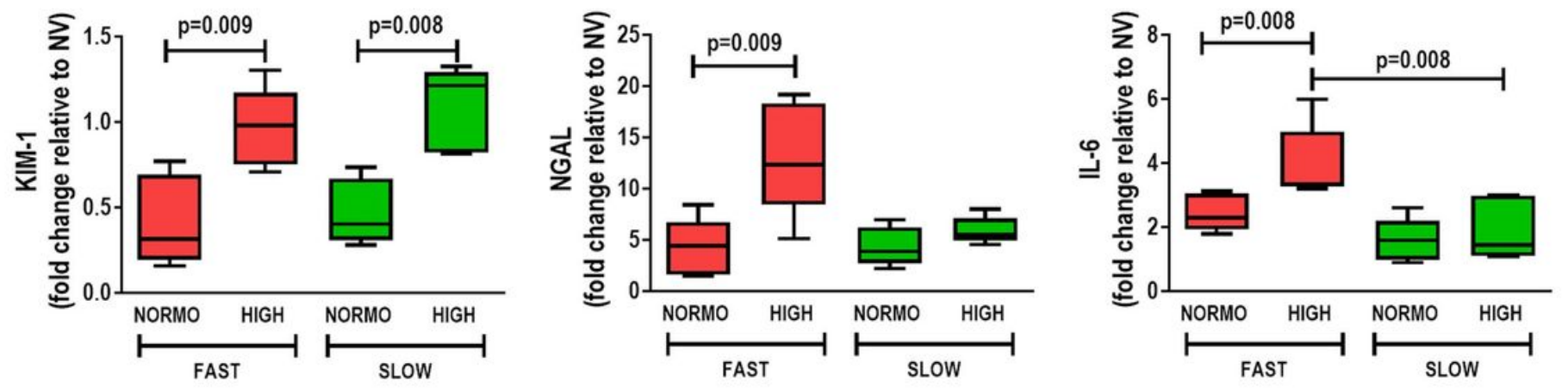

\section{Figure 5}

Expression of biologic markers associated with renal tubular epithelial cell damage [kidney injury molecule (KIM)-1 and neutrophil gelatinase-associated lipocalin (NGAL)] and inflammation [interleukin (IL)-6]. Relative gene expression was calculated as a ratio of the average gene expression levels compared with the reference gene (acidic ribosomal phosphoprotein P0, 36B4) and expressed as fold change relative to non-ventilated animals (NV). Boxes show the interquartile (25 to $75 \%$ ) range, whiskers encompass the range (minimum to maximum), and horizontal lines represent median values of 7 animals/group. Rats received standard [10 mL/kg/h (NORMO)] or high [30 mL/kg/h (HIGH)] volume of Ringer's lactate. FAST: abrupt PEEP decrease from 9 to $3 \mathrm{cmH} 2 \mathrm{O}$. SLOW: gradual PEEP decrease $(0.2$ $\mathrm{cmH} 2 \mathrm{O} / \mathrm{min}$ ) from 9 to $3 \mathrm{cmH} 2 \mathrm{O}$.

\section{Supplementary Files}

This is a list of supplementary files associated with this preprint. Click to download.

- AdditionalFile5.docx

- AdditionalFIle4.docx

- AdditionalFile3.docx

- AdditionalFile2.docx 
- AdditionalFile1.docx

Page 25/25 